\title{
Reduced Losses in Die-Cast Machines With Insulated Rotors
}

\author{
Yali N. Feng, Member, IEEE, Judith Apsley, Member, IEEE, Steve Williamson, Fellow, IEEE, \\ Alexander C. Smith, Senior Member, IEEE, and Dan M. Ionel, Senior Member, IEEE
}

\begin{abstract}
This paper reports an investigation into the influence of interbar currents on the performance of die-cast cage induction machines. This work is based on an extensive set of experimental measurements using a series of specially made die-cast cage induction motors with bars insulated using alternate processes. Experimental measurements were undertaken separately by the industrial manufacturer and at the university laboratories, and these clearly demonstrate that increasing the insulation of the rotor cage inhibits the flow of interbar current and reduces the total motor losses and increases the motor efficiency as a consequence. The experimental measurements were further validated using an analytical interbar model. Further experimental measurements also demonstrate that insulating the rotor cage also modifies the stator torque in a counterintuitive fashion.
\end{abstract}

Index Terms-Cage induction motor, interbar current losses.

\section{INTRODUCTION}

$\mathbf{T}$ HE IMPORTANCE of increasing machine efficiency is universally acknowledged. The concerns over "greenhouse" gas emissions and shrinking supplies of nonrenewable energy resources (particularly gas and oil) know no international boundaries. A range of legislation and guidance policies have been established throughout the world with the goal to mandate higher efficiency for most popular motor ratings [1].

However, higher efficiency motors come at a higher price because such motors are generally made by using increased volumes of active materials. The market penetration by such motors in areas where their use is not mandatory has been below expectation. There is clearly a need to remain cost competitive in the manufacture of high-efficiency motors and to develop lower loss motor designs without significantly increasing cost. This requires a good understanding of the mechanisms that produce loss in the machine. Die-cast cage induction machines

Paper 2009-EMC-141.R1, presented at the 2009 IEEE International Electric Machines and Drives Conference, Miami, FL, May 3-6, and approved for publication in the IEEE TRANSACTIONS ON INDUSTRY APPLICATIONS by the Electric Machines Committee of the IEEE Industry Applications Society. Manuscript submitted for review May 29, 2009 and released for publication September 14, 2009. First published March 22, 2010; current version published May 19, 2010. This work was supported by the A. O. Smith Corporation.

Y. N. Feng is with Dowding and Mills Engineering Services, Birmingham, B12 0JJ, U.K. (e-mail: natalie.feng@ dowdingandmills.com).

J. Apsley and A. C. Smith are with the School of Electrical and Electronic Engineering, The University of Manchester, Manchester, M60 1QD, U.K. (e-mail: j.apsley@manchester.ac.uk; sandy.smith@manchester.ac.uk).

S. Williamson is with the University of Surrey, Guildford, GU2 7XH, U.K (e-mail: Steve.Williamson@surrey.ac.uk).

D. M. Ionel is with the A. O. Smith Corporate Technology Center, Milwaukee, WI 53224-9512 USA (e-mail: dan.ionel@ieee.org).

Color versions of one or more of the figures in this paper are available online at http://ieeexplore.iee.org.

Digital Object Identifier 10.1109/TIA.2010.2045094 are commonly and widely used in industrial and domestic applications. In such machines, the presence of interbar current introduces additional losses, which are one of the main components of stray loss [2], [3] and are difficult to predict precisely. Some manufacturers use proprietary means to insulate rotor cages, prior to casting, in an attempt to reduce interbar currents. In this paper, interbar current losses are investigated using accurate experimental measurement, to explore the evidence for loss reduction in rotors with improved insulation. An analytical model has been developed in a previous work [4], [5], from which the losses due to the interbar current can be predicted. The losses calculated analytically using that model are also compared with those measured experimentally.

The presence of interbar current has an effect not only on increasing the additional motor losses but also in increasing the motor starting torque, and discussion of this is also given in this paper.

\section{Industrial InVESTIGATION OF TOTAL MOTOR LOSS}

The industrial partner in this work carried out an extensive investigation of the effects of a range of manufacturing processes on the efficiency of their cage machines. As part of this investigation, the effect of using alternative procedures for increasing the resistance between the rotor bars and the rotor lamination iron was examined. Two batches of 28 rotors of identical design were manufactured. The first batch, which had a lower grade of bar-to-iron insulation, is identified in this paper by the batch reference letter "N," together with an individual number. The second batch, which had a higher grade of insulation, is similarly identified by the letter "S." Within each batch, other manufacturing parameters were also varied, such as temperature, etc., but in this paper, we shall focus solely on the bar insulation. The designatory letters and numerals, such as S21 or N6, are therefore used only to identify individual rotors in each batch. The only difference between the two rotors with the same number (e.g., S22 and N22) is the process used for insulating the bars. On the other hand, the bars of two rotors with the same designatory letter (e.g., S22 and S8) were insulated using the same process, but with varying manufacturing parameters, such as temperature, etc.

The performance of all of the rotors was measured by the manufacturer using the same pair of stators, one single phase and one three phase. Overall, efficiency was determined by the input/output method. The total motor loss measured at rated output power with a single-phase stator during these tests is shown in Fig. 1, in which the losses measured with the S-type 


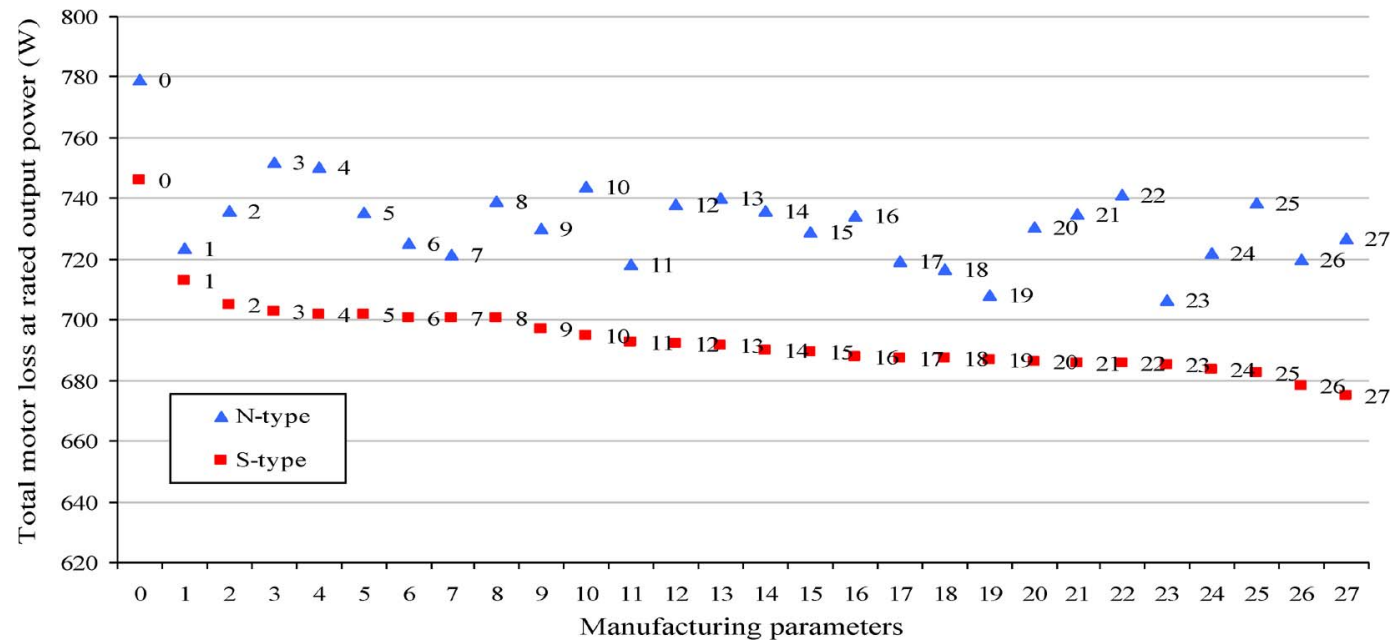

Fig. 1. Measured total loss at rated output power (in watts) with single-phase stator.

rotors are presented in order of diminishing value from left to right. S0 produces the highest loss of any of the S-type rotors and S27 the lowest. The loss with each of the N-type rotors is shown in the same column as its S-type numerical counterpart.

The results shown in Fig. 1 indicate that, in addition to the variation between pairs of rotors, there is a clear and systematic difference between the $\mathrm{N}$-type and $\mathrm{S}$-type. It provides strong evidence of the significant reduction in the motor loss gained from the enhanced cage insulation of the S-type rotors. To investigate further, five rotors were selected for detailed investigation in the university laboratory. The rotors chosen were N0, N5, N25, S0, and S3.

\section{INVESTIGATION OF INTERBAR-CURRENT LOSS}

Reference [6] describes in detail the design and use of a precision calorimeter to measure the losses in an induction machine directly. This approach has been adopted by the present authors, who followed the design and test methods given in [6]. This test facility enabled the losses in a number of single- and three-phase motors with different rotor-bar insulation to be determined. The calorimeter and the method by which the motor losses are determined are summarized briefly in Section III-A. Similarly, an analytical model described in [4] and [5], which takes into account the interbar currents in the calculation of the motor losses, is summarized in Section III-B. One of the major parameters required for the analytical model is the value of the interbar resistance, which forms part of the input data. Careful measurements have been carried out to obtain the interbar resistance for both insulated and uninsulated rotors, following the method given in [7]. This work is described in Section III-C.

\section{A. Calorimeter Test Facility}

The calorimeter used for loss measurement is shown in Fig. 2. Its constructional details closely follow those described in [6]. The calorimeter box is enclosed and thermally well insulated. The test motor was placed close to the center of the box. As shown in Fig. 2, there are two accesses for air which flows into and out of the calorimeter, an air inlet and an air outlet. When the test motor is excited, all of its losses

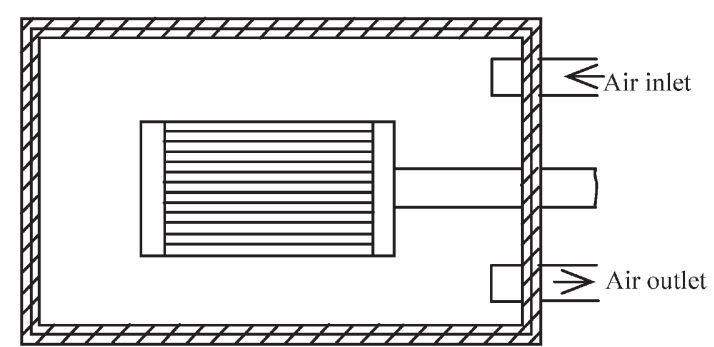

Fig. 2. Schematic of calorimeter.

emerge as heat which increases the temperature of air inside of the calorimeter box. When thermal equilibrium is reached inside the calorimeter, the difference in temperatures between the inlet air and outlet air, together with the knowledge of the flow speed and the physical properties of air, enables the loss produced by the motor to be determined. The heat energy can be found using

$$
P_{c}=\left(3.5 P_{A}+4 P_{W}\right) \frac{d V}{d t} \frac{T_{\mathrm{out}}-T_{\mathrm{in}}}{T_{\mathrm{abs}}}
$$

where

$P_{c} \quad$ calorimeter indicated power (in watts);

$P_{A} \quad$ partial pressure of inlet air (in pascal);

$P_{W} \quad$ partial pressure of water vapor of inlet air (in pascal);

$d V / d t \quad$ volumetric air flow rate (in cubic meters per second);

$T_{\text {out }} \quad$ outlet air temperature (in degree centigrade);

$T_{\mathrm{in}} \quad$ inlet air temperature (in degree centigrade);

$T_{\text {abs }} \quad$ absolute air temperature (in kelvin).

Using (1), the total power loss $P_{c}$ can be obtained from the calorimeter measurement, and this will be equal to the total motor loss if the motor is the only heat source inside the calorimeter box. As will be seen from (1), the accuracy of $P_{c}$ depends on several measurements of temperature, air pressure, and mass air flow. For this reason, the most advanced sensor instruments available must be used to achieve high accuracy for each of the elements required in (1). Temperatures $\left(T_{\mathrm{in}}, T_{\text {out }}\right.$, and $\left.T_{\mathrm{abs}}\right)$ are measured using Pt100 resistive temperature devices (RTDs). To make sure that the temperature measurements are correct, two RTDs were installed in the middle of the inlet in the 


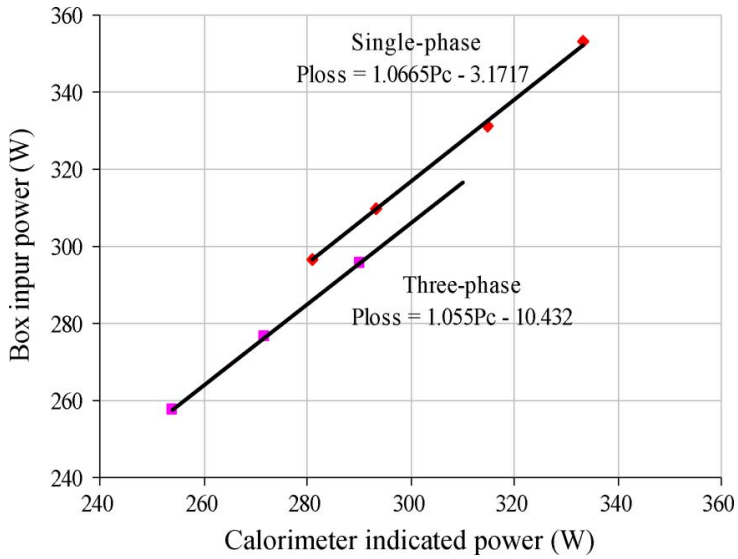

Fig. 3. Calibration curves of calorimeter.

calorimeter and another two in the outlet. All these thermocouple probes are calibrated and have an accuracy of $-0.05{ }^{\circ} \mathrm{C}$. The air pressure is measured via a Druck DP1760 precision pressure indicator, with an accuracy of \pm 0.15 mbar. This air pressure is used to obtain the variables of $P_{A}$ and $P_{W}$ as required in (1), with the use of the relative humidity (RH) of air which is measured via a Vaisala HMP233 humidity and temperature transmitter with an accuracy of $\pm 1 \% \mathrm{RH}$. The variable $d V / d t$ in (1) is obtained from the air mass flow-rate frequency which is measured via a Quadrina QFG75B/A full-flow turbine.

The measurement of motor loss using a calorimeter is time consuming because the system needs to achieve thermal equilibrium for (1) to be valid. To achieve this equilibrium, the inlet air should be at constant temperature and flow into the box at a constant mass flow rate. The air flowing into the box is taken from the normal ambient atmosphere cooled at the desired temperature which is controlled by a Eurothem 2132 proportional-integral (PI) controller connected to a chiller. In the steady state, the temperature variation of the inlet-air temperature is kept between $\pm 0.1{ }^{\circ} \mathrm{C}$. The mass air flow is controlled by an inverter used to excite an induction motor that drives a fan to blow the air into the box. By adjusting the speed of the induction motor via the inverter, the required mass flow rate of the inlet air can be achieved.

The design of the calorimeter takes into account the heat loss leaking from the inside of the box to the outside. The calorimeter walls are made of two 12-mm-thick aluminum sheets separated by an insulating material. The outer walls are heated by resistors and constrained to have a temperature that is equal to that of the inner walls. These heaters are housed in the insulation and controlled via the Eurotherm 2132 PI controller. The motor support bed, which is installed inside the calorimeter box, is supported by four metal legs passing from within the calorimeter to the outside. To minimize the heat conducted through the legs, external heaters are used and also controlled by the Eurothem 2132 PI controller.

Although every precaution is taken to reduce heat leakage from the calorimeter, it can never be eliminated. The calorimeter error is taken into account by a calibration test in which a resistive load is placed inside the box and excited to provide a known rate of Joule loss, producing the calibration curves shown in Fig. 3. It can be seen that in Fig. 3, there are two calibration curves, one for single-phase motors and another for three-phase motors. The shaft and bearing arrangements however were different for these and so the calibration tests were carried out immediately after each set of motor tests to make sure that both were performed under equivalent test conditions.

These calibration curves allow the actual motor loss $P_{\text {loss }}$ to be determined from the indicated loss $P_{c}$ by (2) and (3).

For the single-phase machine,

$$
P_{\text {loss }}=1.0665 P_{c}-3.1717 .
$$

For the three-phase machine,

$$
P_{\text {loss }}=1.055 P_{c}-10.432 \text {. }
$$

All five selected rotors, N0, N5, N25, S0, and S3, have been tested in the calorimeter using the same single-phase stator and the same three-phase stator. ${ }^{1}$ Ten stator/rotor combinations were therefore examined. The rated rms line voltage is $115 \mathrm{~V}$ for the single-phase test motors and $230 \mathrm{~V}$ for the threephase motors. The machines were excited by a separate $60-\mathrm{Hz}$ generator, to avoid problems caused by harmonic distortion in the laboratory supply. The load of the test motor was provided by a dynamometer loading rig, controlled by a Ward Leonard motor-generator set.

\section{B. Analytical Model}

This analytical model allows the presence of the interbar currents to predict motor performance, such as loss and torque. Previous work has shown that interbar current has an impact on the harmonic loss at full load and starting torque for locked rotor [4], [5].

This analytical model was initially developed for a rotor model in which the interbar currents are assumed to flow only between adjacent bars. Following further investigation, an alternative rotor model was proposed in which the interbar currents flow into and around the rotor core. The validity of this new rotor model was verified by means of measurements made on 54 rotors of identical design [9]. This new rotor model was then incorporated into the existing analytical model to redefine the relationship between the resistance parameter in the analytical model and the effective bar-to-bar resistance measured under test. The measured effective bar-to-bar resistance is used to determine a single interbar resistance which is required for the calculation of the resistance parameter in the analytical model; this is discussed in Section III-C.

In this new rotor model, the interbar current is assumed to flow from the bar to the rotor core through a bar-to-core contact resistance, and then around the core. The expression for the effective interbar resistance is then derived using the contact resistance and the core resistance, in much the same way that an effective rotor bar resistance is calculated using the actual bar resistance and the resistance of the end rings. However, in [8], it is shown that the core resistance is negligible and can be ignored without causing significant errors. This greatly

\footnotetext{
${ }^{1}$ N.B. The stators used in the manufacturer's tests were no longer available and so the stators used in the calorimeter tests were different from those used by the manufacturer.
} 


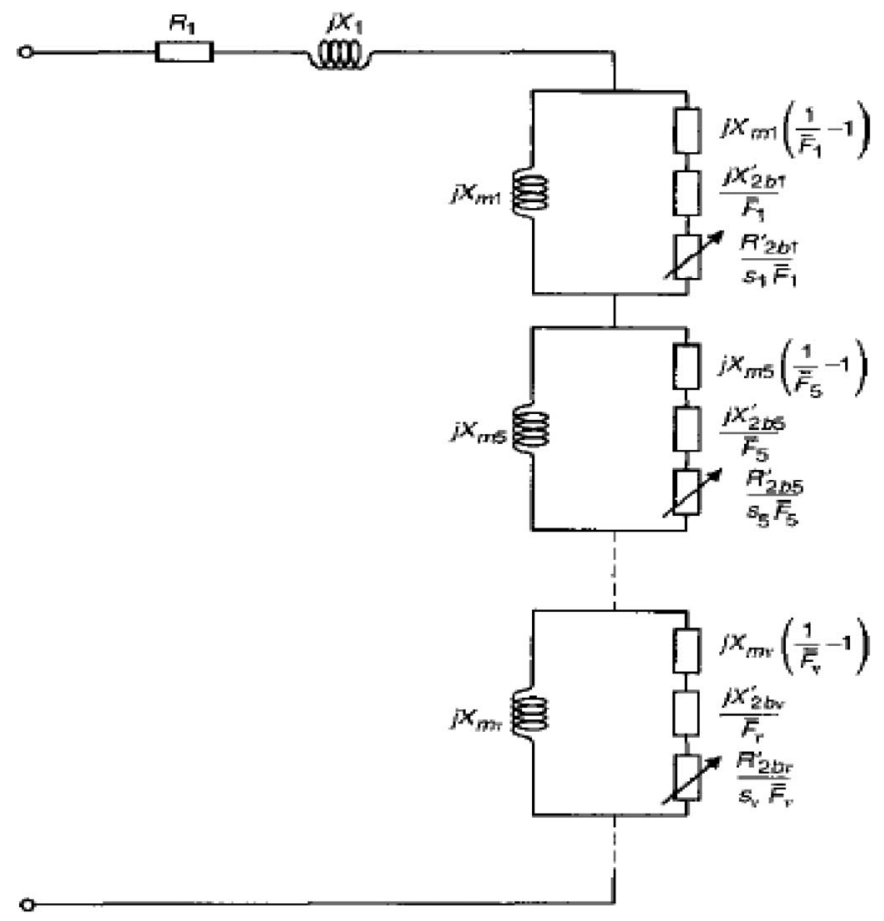

Fig. 4. Chain equivalent circuit for a balanced three-phase motor with an uninsulated cage rotor.

simplifies the calculation of the resistance parameter in the analytical model.

In [8], the authors derive a per-phase equivalent circuit for a balanced three-phase cage induction machine, allowing for MMF harmonics, interbar currents, and rotor skew. This is shown in Fig. 4, which has a recognizable form except for the inclusion of the parameter $\bar{F}_{v}$ in place of the conventional skew factor. However, the familiarity between Fig. 4 and the conventional chain equivalent circuit must not be confused with equivalence. The parameter $R_{2 b v}^{\prime}$ in the rotor branch in Fig. 4 is determined by two terms. One term is the conventionally calculated rotor resistance, referred to the stator, without the contribution due to the end rings; the other term is the modification which accounts for the imperfect bar-to-iron insulation. $X_{2 b v}^{\prime}$ is the conventionally calculated rotor leakage reactance, referred to the stator, omitting any contribution for end-ring leakage. Therefore, in Fig. 4, $R_{2 b v}^{\prime}$ and $X_{2 b v}^{\prime}$ for the vth harmonic do not include any contribution due to the impedance of the end ring. The impedance of the end ring is embedded in the slip-dependent harmonic factor which is incorporated in the complex interbar factor $\bar{F}_{v}$. The factor $\bar{F}_{v}$ also involves the rotor-skew angle and interbar resistance. In Fig. $4, R_{1}$ and $X_{1}$ are the stator self-impedance, and $X_{m v}$ is the $v$ th harmonic magnetizing reactances of the machine, which are calculated in the normal manner.

For an insulated cage rotor, the interbar resistance can be regarded as infinite. Under these circumstances, the expression for the factor $\bar{F}_{v}$ is greatly simplified, and the equivalent circuit reduces to the familiar chain per-phase equivalent circuit for a three-phase cage induction machine, which is shown in Fig. 5. In Fig. 5, the parameters $R_{2 v}^{\prime}$ and $X_{2 v}^{\prime}$ are the conventionally calculated $v$ th harmonic rotor impedance, referred to the

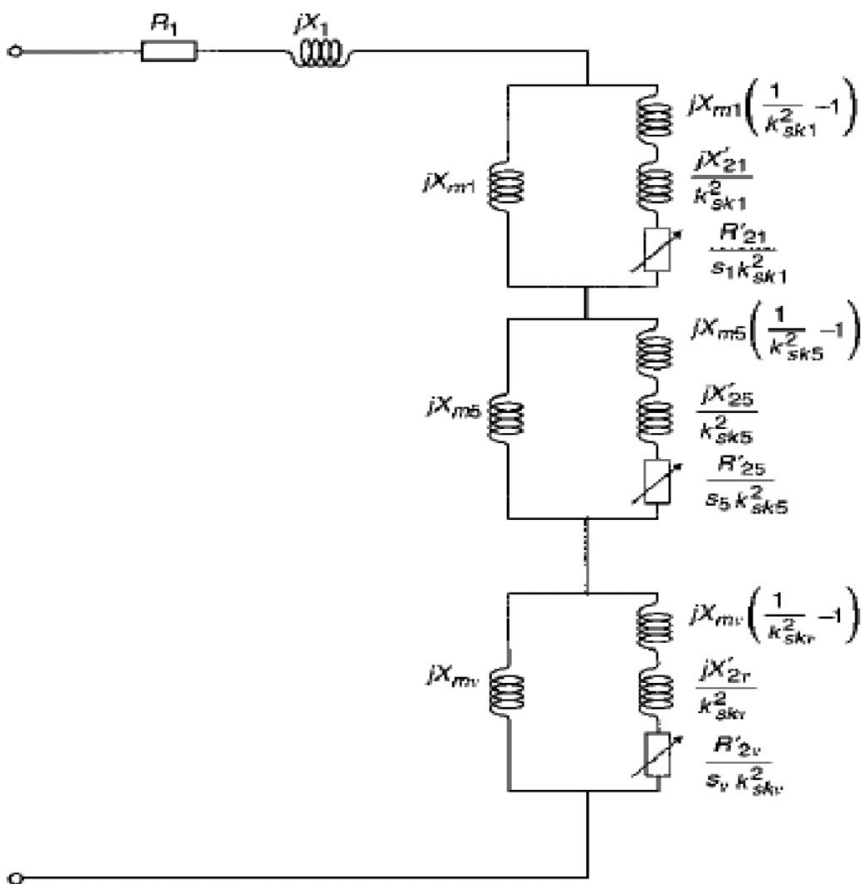

Fig. 5. Chain equivalent circuit for a balanced three-phase motor with an insulated cage rotor.

stator, incorporating the end-ring impedance. $K_{s k v}$ is the $v$ th harmonic skew factor, calculated in the normal manner.

The power and torque relationships that apply to an insulated cage motor also apply to a motor with an uninsulated cage rotor. The power transferred to the rotor via the $v$ th harmonic air-gap field is found by

$$
P_{2 v}=3 I_{1}^{2} \operatorname{Re}\left\{\bar{Z}_{2 v}\right\}
$$

where $I_{1}$ is stator current and $\bar{Z}_{2 v}$ is the vth harmonic rotorbranch impedance in the equivalent circuit. The motor loss for the $v$ th harmonic can then be found by (5) for a specified rotor speed represented by the harmonic slip $s_{v}$

$$
P_{\text {loss }}^{\nu}=s_{v} P_{2 v} .
$$

The torque due to the $v$ th harmonic field is given by

$$
T_{v}=\frac{v p}{\omega} P_{2 v}
$$

where $\omega$ is fundamental angular frequency and $p$ is the number of pole pairs. Using (4) and (5), the efficiency for the $v$ th harmonic can then be readily found by

$$
\eta_{\nu}=\frac{P_{2 v}}{P_{2 v}+P_{\text {loss }}^{\nu}} .
$$

As outlined earlier, this equivalent circuit does not allow for iron loss, windage, or friction loss. These may be accommodated in the conventional manner. However, in this paper, we are concerned with the reduction in loss that is achieved by insulating the rotor cage. As the loss produced by the interbar currents is a Joule loss, detailed iron-loss calculations are omitted for the sake of simplicity. In this paper, the equivalentcircuit model of Fig. 4 is therefore used to determine the difference in loss, rather than the absolute value of the total loss. 


\section{Determination of Interbar Resistance}

The calculation of the complex harmonic interbar factor $\bar{F}_{v}$, which forms part of the equivalent-circuit model, requires as data a harmonic interbar-resistance parameter $r_{q v}^{\prime}$. If the resistance of the iron core to interbar currents is assumed negligible, this parameter is simply the resistance between the rotor bar and the iron core per meter length of the core. While straightforward to define, it is less easily obtained. The first step involves the direct measurement of the apparent resistance between adjacent pairs of rotor bars, $R_{\text {eff }}$. This measurement is not without difficulty, due partly to the fact that it is often on the same order of magnitude as the bar resistance itself and partly due to the implicit underlying assumption that the bar-to-iron contact resistance is uniform along the length of each bar. The usual method employed is to remove the end rings and one or two laminations to be sure of eliminating the contact resistance caused by the machining process. Then, a dc current is injected into one end of a bar and extracted from an adjacent bar at the same end of the rotor [7], while the voltage between them is measured with a precision voltmeter. There are 48 bars for each test rotor (type $\mathrm{N}$ and type $\mathrm{S}$ ). Therefore, the apparent bar-to-bar resistance is measured for 48 adjacent pairs. $R_{\text {eff }}$ is calculated from the average value of the 48 apparent resistances. This experimentally determined resistance includes elements of the rotor-bar resistance. However, as previously recorded [7], the bar-to-bar resistance may be calculated by

$$
\begin{aligned}
R_{\mathrm{eff}} & =r_{\mathrm{BB}(\mathrm{ex})} \cdot \frac{\sqrt{\alpha}}{\sinh (L \sqrt{\alpha})} \\
\alpha & =\frac{2 r_{B}}{r_{\mathrm{BB}(\mathrm{ex})}}
\end{aligned}
$$

where $r_{\mathrm{BB}(\mathrm{ex})}$ is the interbar resistance of unit axial core length, in ohm-meters; $R_{\text {eff }}$ is the measured effective bar-tobar resistance, in ohms; $r_{B}$ is the rotor bar resistance per unit axial length of core, in ohms per meter; and $L$ is the axial rotor core length, in meters. As the resistance of the iron core to interbar currents has been assumed to be negligible, the harmonic interbar resistance parameter $r_{q v}^{\prime}$ is simply half the bar-to-bar resistance, i.e.,

$$
r_{q v}^{\prime}=\frac{r_{\mathrm{BB}(\mathrm{ex})}}{2}
$$

The measured results for $R_{\text {eff }}$ and the calculated values for the interbar resistance $r_{\mathrm{BB}(\mathrm{ex})}$ are given in Section IV-C.

\section{RESUlts AND Discussion}

\section{A. Test Results With the Single-Phase Stator}

The single-phase machine was tested at a full-load speed of $1725 \mathrm{r} / \mathrm{min}$. The raw test data is given in Table I. It will be noted that the actual voltages measured varies slightly from test to test and so the test results have been scaled to the rated voltage of $115 \mathrm{~V}$ and presented in Table II to allow the comparison of losses at the same supply voltage. The rules applied for the scaling are the following:

scaling factor (rated voltage)/(measured voltage); current (measured current $) \times($ scaling factor $)$;
TABLE I

MeAsured Results of Single-Phase Motors at 1725 r/min

\begin{tabular}{|l|c|c|c|c|c|}
\hline Rotor type & $\mathrm{N} 0$ & $\mathrm{~N} 5$ & $\mathrm{~N} 25$ & $\mathrm{~S} 0$ & $\mathrm{~S} 3$ \\
\hline Voltage (V) & 110.3 & 110.51 & 110.4 & 110.49 & 110.5 \\
\hline Current (A) & 11.91 & 12.19 & 11.98 & 11.66 & 11.73 \\
\hline Power Factor & 0.7 & 0.696 & 0.703 & 0.702 & 0.697 \\
\hline Input Power (W) & 920.38 & 938.02 & 930.22 & 904.58 & 902.86 \\
\hline Motor Losses (W) & 330.67 & 338.28 & 333.49 & 304.86 & 305.11 \\
\hline Output Power (W) & 589.71 & 599.74 & 596.73 & 599.71 & 597.75 \\
\hline Torque (Nm) & 3.26 & 3.32 & 3.3 & 3.32 & 3.31 \\
\hline
\end{tabular}

TABLE II

SCALED Results of Single-Phase Motors at 1725 r/min

\begin{tabular}{|l|c|c|c|c|c|}
\hline Rotor type & N0 & N5 & N25 & S0 & S3 \\
\hline Voltage (V) & \multicolumn{5}{|c|}{115} \\
\hline Current (A) & 12.42 & 12.68 & 12.48 & 12.14 & 12.21 \\
\hline Input Power (W) & 1000.5 & 1015.8 & 1009.3 & 979.86 & 977.96 \\
\hline Motor Losses (W) & 359.45 & 366.31 & 361.85 & 330.24 & 330.49 \\
\hline Output Power (W) & 641.04 & 649.44 & 647.49 & 649.62 & 647.47 \\
\hline Torque (Nm) & 3.55 & 3.6 & 3.58 & 3.6 & 3.58 \\
\hline Efficiency (\%) & 64.07 & 63.94 & 64.15 & 66.30 & 66.21 \\
\hline
\end{tabular}

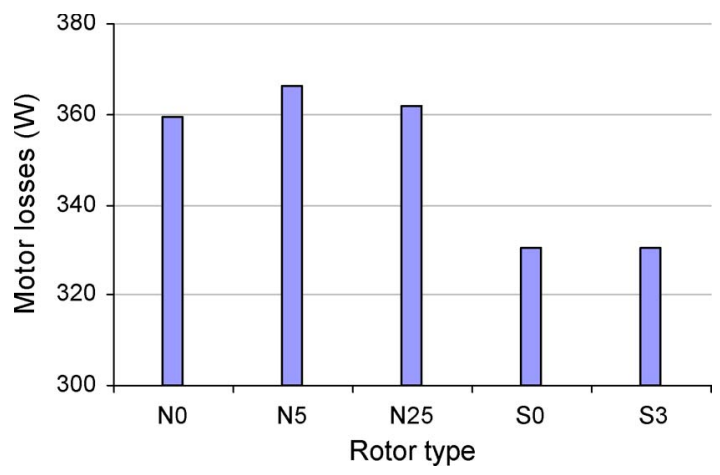

Fig. 6. Scaled motor loss for single-phase machine.

input power $\quad($ measured input power $) \times(\text { scaling factor })^{2}$;

loss

output power

torque (measured loss $) \times(\text { scaling factor })^{2}$;

(input power) - (loss);

(output power)/(speed).

The remaining results presented in this section will be the scaled values using the same procedure. The five rotor samples are identified by N0, N5, and N25, and S0 and S3. Table II clearly shows that the type- $\mathrm{N}$ rotors have higher loss than the type-S rotors. The average loss for type-N rotors is $334 \mathrm{~W}$, while the average loss for type $\mathrm{S}$ rotor is $305-\mathrm{W}$. The reduction in motor loss caused by using a type $\mathrm{S}$ rotor is $29 \mathrm{~W}$ for this single-phase machine. The gain in efficiency arising from the insulation of the rotor cage is approximately 2.2 percentage points. The motor loss and efficiency for all rotors in the singlephase stator, measured using the calorimeter, is also shown in Figs. 6 and 7, clearly demonstrating the reduced motor loss and consequently, the improved motor efficiency for rotor samples S0 and S3.

\section{B. Test Results With the Three-Phase Stator}

Using the calorimeter test facility, the same rotors were tested with a three-phase stator at $1725 \mathrm{r} / \mathrm{min}$. The raw test data were 


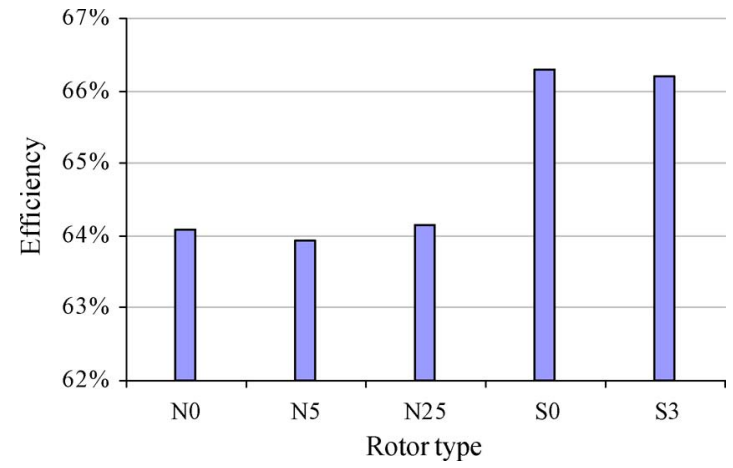

Fig. 7. Motor efficiency for single-phase machine.

TABLE III

SCAled Results of Three-Phase Motors at $1725 \mathrm{r} / \mathrm{min}$

\begin{tabular}{|l|c|c|c|c|c|}
\hline Rotor type & N0 & N5 & N25 & S0 & S3 \\
\hline Voltage (V) & \multicolumn{5}{|c|}{230} \\
\hline Current (A) & 3.49 & 3.53 & 3.48 & 3.45 & 3.41 \\
\hline Input Power (W) & 958.87 & 964.38 & 959.16 & 950.51 & 934.74 \\
\hline Motor Losses (W) & 277.74 & 287.46 & 278.49 & 264.23 & 262.22 \\
\hline Output Power (W) & 681.13 & 676.93 & 680.67 & 686.28 & 672.52 \\
\hline Torque (Nm) & 3.77 & 3.75 & 3.77 & 3.80 & 3.72 \\
\hline Efficiency (\%) & 71.03 & 70.19 & 70.97 & 72.20 & 71.95 \\
\hline
\end{tabular}

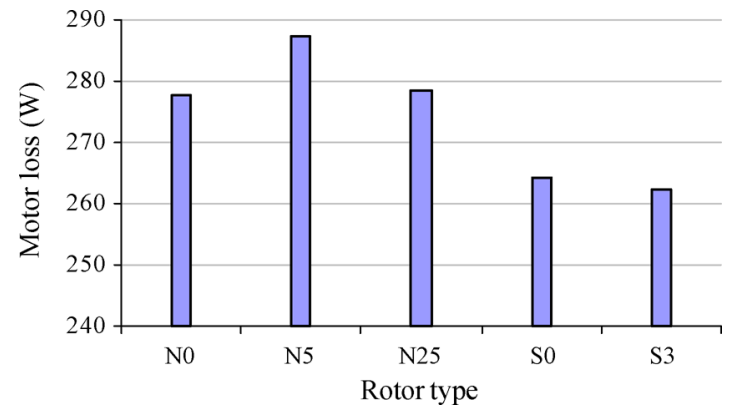

Fig. 8. Scaled motor loss for three-phase machine at $1725 \mathrm{r} / \mathrm{min}$.

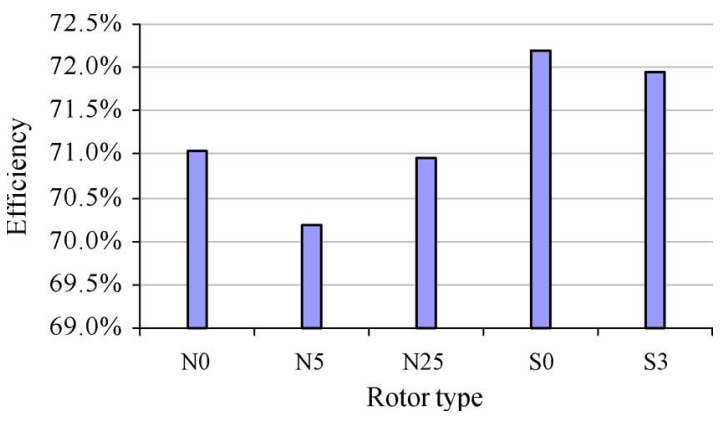

Fig. 9. Motor efficiency for three-phase machine at $1725 \mathrm{r} / \mathrm{min}$.

scaled to the rated voltage of $230 \mathrm{~V}$ for purposes of comparison. The scaled results are given in Table III. The total average loss for the three-phase motor with an N-type rotor is $281 \mathrm{~W}$ while that for the type-S rotors is $263 \mathrm{~W}$. This is an $18-\mathrm{W}$ reduction in the total loss, which equates to a 1.4-percentagepoint increase of efficiency for this test machine with type-S rotors. The comparison of the motor loss and efficiency for this three-phase stator with all five test rotor samples is shown in Figs. 8 and 9, showing the improvement of the motor efficiency achieved using type-S rotors.
TABLE IV

SCAlEd Results of Three-Phase Motors at 1735 r/min

\begin{tabular}{|l|c|c|c|c|c|}
\hline Rotor type & N0 & N5 & N25 & S0 & S3 \\
\hline Voltage (V) & \multicolumn{5}{|c|}{230} \\
\hline Current (A) & 3.37 & 3.40 & 3.36 & 3.32 & 3.29 \\
\hline Input Power (W) & 873.84 & 878.50 & 873.78 & 864.98 & 850.25 \\
\hline Motor Losses (W) & 258.91 & 266.28 & 258.85 & 245.58 & 243.42 \\
\hline Output Power (W) & 614.93 & 612.23 & 614.92 & 619.40 & 606.83 \\
\hline Torque (Nm) & 3.38 & 3.37 & 3.38 & 3.41 & 3.34 \\
\hline Efficiency (\%) & 70.37 & 69.69 & 70.38 & 71.61 & 71.37 \\
\hline
\end{tabular}

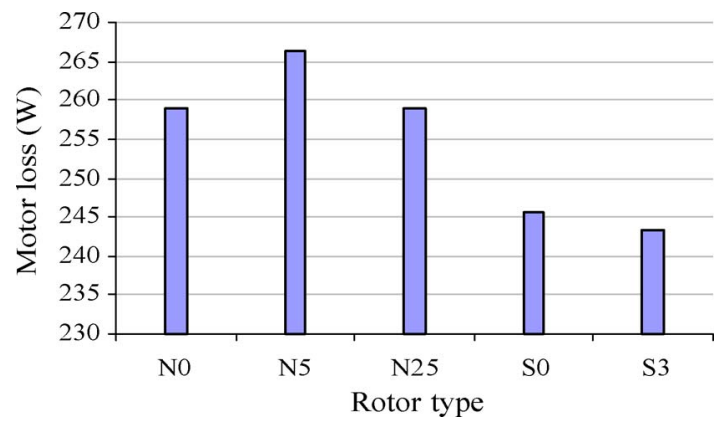

Fig. 10. Scaled motor loss for three-phase machine at $1735 \mathrm{r} / \mathrm{min}$.

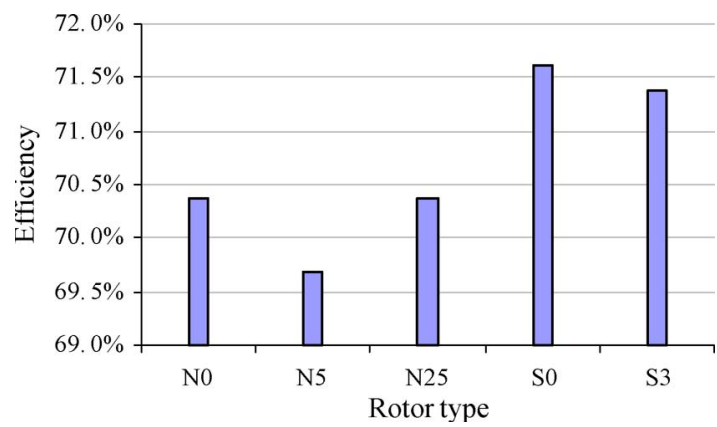

Fig. 11. Motor efficiency for three-phase machine at $1735 \mathrm{r} / \mathrm{min}$.

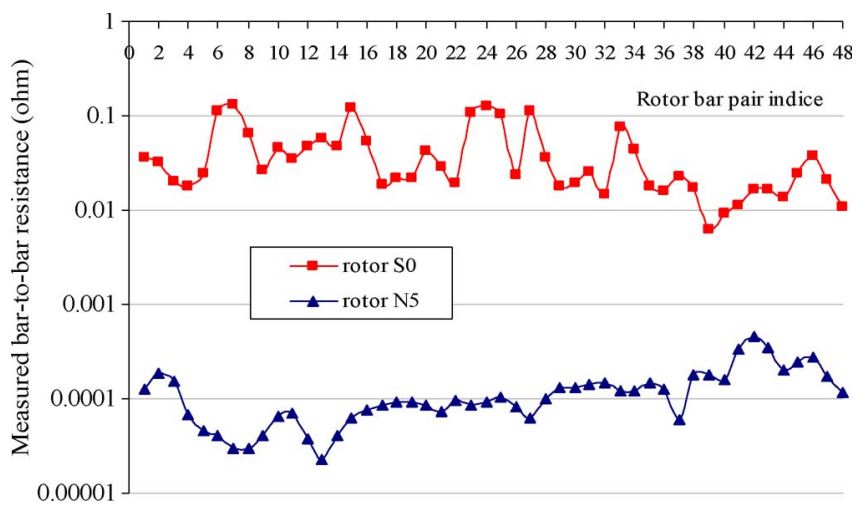

Fig. 12. Measured bar-to-bar resistance for rotors.

The calorimeter tests were repeated with the three-phase stator and a rotor speed of $1735 \mathrm{r} / \mathrm{min}$. The experimental results showed the same trends. The scaled data for rated voltage are presented in Table IV. The data in Table IV now reveals that the average loss measured in the type- $\mathrm{N}$ rotors was $261.3 \mathrm{~W}$ while that in the type $\mathrm{S}$ was $244.5 \mathrm{~W}$; a reduction of $16.8 \mathrm{~W}$. This equates to an increase in efficiency of $1.4 \%$. The comparison for the total motor loss and efficiency for all type- $\mathrm{N}$ and type-S rotor samples is also shown in Figs. 10 and 11. 


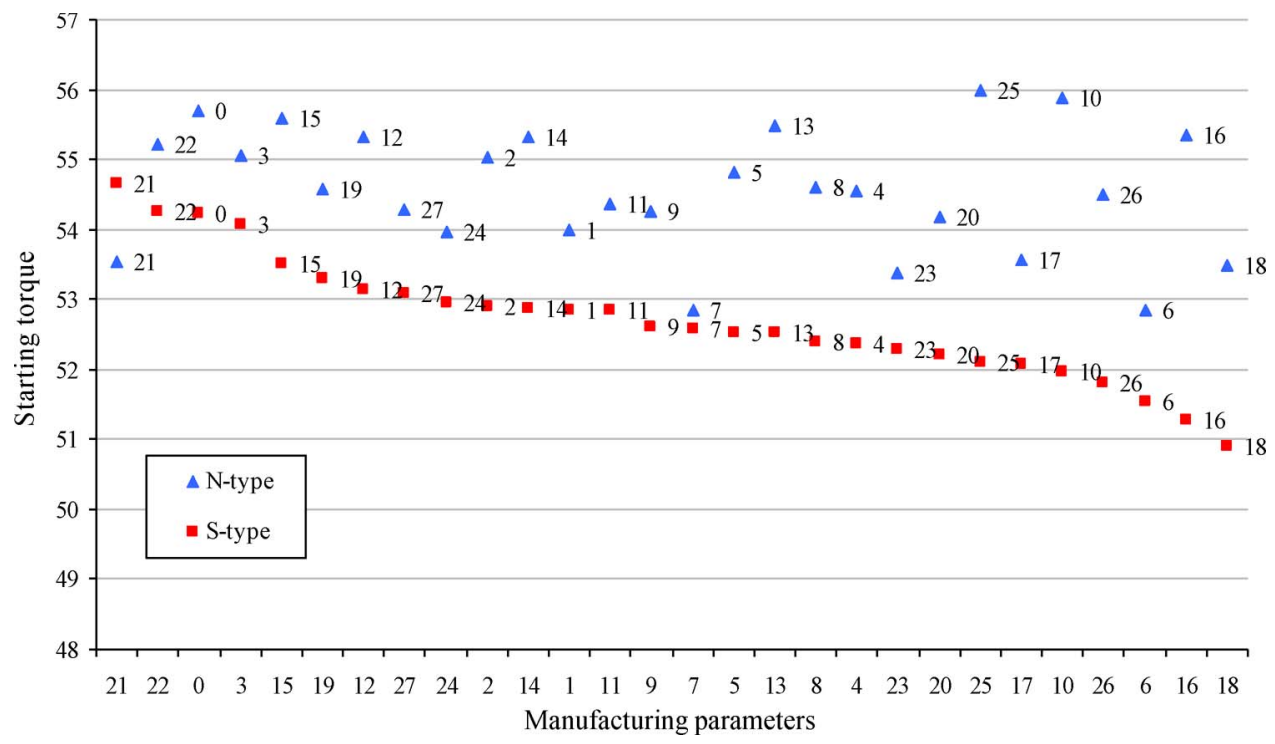

Fig. 13. Measured starting torque (in ounce-feet).

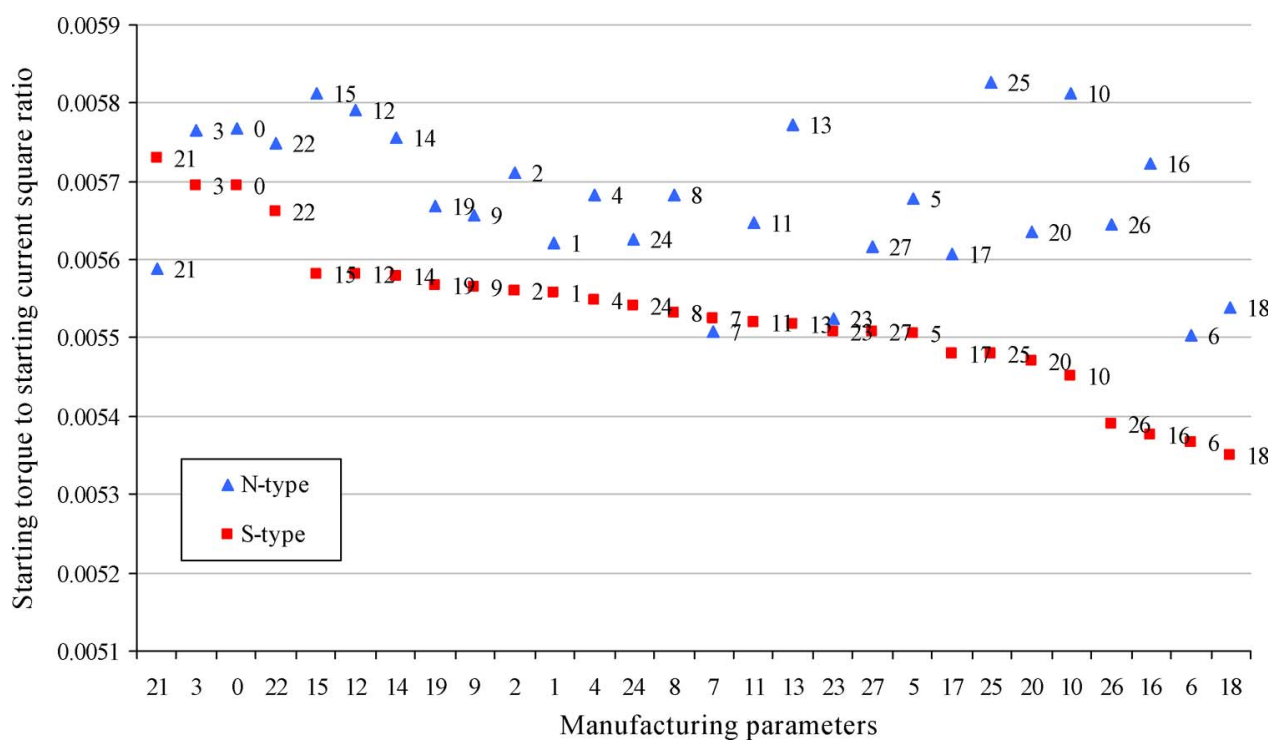

Fig. 14. Measured starting torque to the square of starting current ratio (in ounce-ft per square ampere).

The test results of the single-phase and three-phase cage induction machines, obtained using the calorimeter, have clearly shown that the use of different manufacturing processes to insulate the rotor has produced a variation in total motor loss, with a corresponding change in efficiency. This conclusion reinforced the findings of the extensive set of experimental measurements made on a cage induction machine carried out by the manufacturer, as shown in Fig. 1.

\section{Interbar Resistance Measurement and Analytical Interbar Currents Loss}

The calorimetric tests carried out at Manchester University and the input/output tests carried out in industry have shown that the type-S rotors have a lower loss than type N. An analytical study was therefore carried out to confirm that a reduction in interbar currents is the root cause of this increase in efficiency.
The three-phase machine was used for this part of this work, which began with the careful measurement of the interbar resistance of two rotors; one type $\mathrm{N}$ and one type $\mathrm{S}$. The loss and efficiency results shown in Figs. 6-11, reveal that among the five rotor samples tested in the calorimeter, the uninsulated rotor N5 has the highest motor loss, and the insulated rotor S0 has the lowest motor loss. Hence, these two rotors were chosen for the interbar resistance measurements.

Fig. 12 shows the measured values of the apparent bar-to-bar resistance $R_{\text {eff }}$ for all 48 pairs of rotor bars in rotors N5 and S0, clearly showing that the type-S rotor has an interbar resistance that is two orders of magnitude higher than type N. This graph also demonstrates the variation of the interbar resistance around the periphery of the machine, which has been noted by several authors. The data in Fig. 12 gives average values of $R_{\text {eff }}=$ $4.129 \times 10^{-2} \Omega$ for rotor S0, and $R_{\text {eff }}=1.242 \times 10^{-4} \Omega$ for rotor N5. Equations (8) and (9) then give $r_{\mathrm{BB}(\mathrm{ex})}=2.0989 \times$ $10^{-3} \Omega \cdot \mathrm{m}$ for rotor $\mathrm{S} 0$ and $r_{\mathrm{BB}(\mathrm{ex})}=7.3586 \times 10^{-6} \Omega \cdot \mathrm{m}$ for 
rotor N5. When these values are used in the analytical model, the calculated reduction in losses at $1725 \mathrm{r} / \mathrm{min}$ was $22 \mathrm{~W}$ while that at $1735 \mathrm{r} / \mathrm{min}$ was $18 \mathrm{~W}$. This analytical calculation agrees closely with the losses measured in the calorimeter which gives a loss reduction of $23 \mathrm{~W}$ at $1725 \mathrm{r} / \mathrm{min}$ and $21 \mathrm{~W}$ at $1735 \mathrm{r} / \mathrm{min}$, as shown in Tables III and IV.

\section{Locked-Rotor Torque}

Interbar currents also affect the torque developed by a motor at locked rotor. This has been discussed extensively in [8]. As a supplement to that work, the industrial partner measured the starting performance for all 28 pairs of type- $\mathrm{N}$ and type-S rotors. The results are shown in Fig. 13, showing that the rotors with the lower interbar resistance have the highest starting torque. In Fig. 14, the same locked-rotor data are recast in the form of locked-rotor torque per the square of input current. This parameter is approximately proportional to the effective rotor resistance. The data shown in Fig. 14 indicates that the type-S rotors have a lower effective resistance than the type $\mathrm{N}$, which accords with the observations made on Fig. 13. This is counterintuitive. Improving the insulation between the rotor bars and the rotor lamination iron appears to have reduced the effective cage resistance, rather than increasing it. In fact, this phenomenon was reported in [4] and is shown to arise because a low interbar resistance negates the effect of rotor skew by enabling the phase of the bar current to vary along the bar length in response to the changing phase of the induced electromotive force.

\section{CONCLUSION}

Worldwide legislation now exists to mandate high efficiencies in industrial induction motors. One of the key sources of inefficiency in induction machine is "stray loss," and one of the major components of this is losses due to interbar current in the rotor. A carefully controlled experimental investigation on a batch of rotors with different levels of bar insulation has been undertaken both by the manufacturer and in a university laboratory. Both investigations clearly demonstrate that increasing the insulation between the rotor bars and the rotor iron reduces the total motor losses at full load and part load. The efficiency gains were approximately $2 \%$ for a single-phase stator and $1.4 \%$ for a three-phase stator at full load. The loss reduction measured experimentally agrees closely with that predicted using the analytical model which allows interbar currents. This provides confirmation that the loss reduction observed in the experiments was indeed a consequence of the attenuation of interbar current, rather than any other attendant phenomena. It also confirms the analytical model as a valuable tool for the investigation of the potential loss reduction that can be obtained by insulating the slots in a cast squirrelcage rotor. Experimental measurements have also confirmed previous work by the authors which showed that insulating the rotor cage can modify the starting torque in a manner that is counterintuitive. It is therefore important to consider all aspects of motor performance when deciding whether to insulate a rotor cage. A reliable analytical model is an invaluable tool in that respect.

\section{REFERENCES}

[1] European Scheme Energy Efficiency Classification for Low Voltage AC Motors Designated by CEMEP (European Committee of Manufacturers of Electrical Machines and Power Electronics) and European Commission, 1998. [Online]. Available: www.cemep.org

[2] N. Glew, "Stray load losses in induction motors: A challenge to academia," Power Eng. J., vol. 12, no. 1, pp. 27-32, Feb. 1998.

[3] K. Yamazaki and Y. Haruishi, "Stray load loss analysis of induction motorcomparison of measurement due to IEEE standard 112 and direct calculation by finite-element method," IEEE Trans. Ind. Appl., vol. 40, no. 2, pp. 543-549, Mar./Apr. 2004.

[4] S. Williamson and A. C. Smith, "Equivalent circuits for cage induction motors with inter-bar currents," Proc. Inst. Elect. Eng., vol. 149, no. 3, pt. B, pp. 173-183, May 2002.

[5] S. Williamson and A. C. Smith, "Influence of interbar currents on the harmonic losses and skew in cage induction machines," in Proc. Int. Conf. Power Electron., Mach. Drives (IEE Conf. Publ. No. 487), 2002, pp. 369-375.

[6] P. McLeod, K. J. Bradley, A. Ferrah, R. Magill, J. G. Clare, P. Wheeler, and P. Sewell, "High precision calorimetry for the measurement of the efficiency of induction motors," in Conf. Rec. IEEE IAS Annu. Meeting, 1998, pp. 304-311.

[7] S. Williamson, C. Y. Poh, and A. C. Smith, "Estimation of the inter-bar resistance of a cast cage rotor," IEEE Trans. Ind. Appl., vol. 40, no. 2, pp. 558-564, Mar./Apr. 2004.

[8] S. Williamson and C. Y. Poh, "Inter-bar currents in cage induction motors," Proc. Inst. Elect. Eng.-Elect. Power Appl., vol. 152, no. 5, pp. 1106-1112, Sep. 2005.

[9] C. Y. Poh, "Inter-bar currents in induction motors," Ph.D. dissertation, Univ. Manchester, Manchester, U.K., 2004.

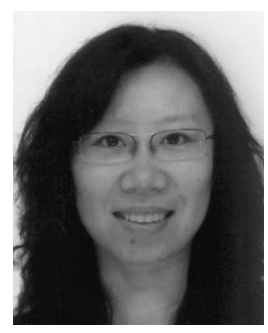

Yali N. Feng (M'07) received the Ph.D. degree from The University of Manchester, Manchester, U.K., in 2006.

She was a Chartered Electrical Engineer with Invensys Brook Crompton Company, Dalian, China. After completing the Ph.D. degree, she became a Research Associate at the University of Manchester. She is currently Technical Manager at Dowding and Mills Engineering Services, Birmingham, U.K. Her main research interests are finite-element analysis of slotting harmonics in cage induction machines, assessment of cage induction machine losses, development of superconducting current limiters for high-voltage application, and design of superconducting motors for long-duration aircraft.

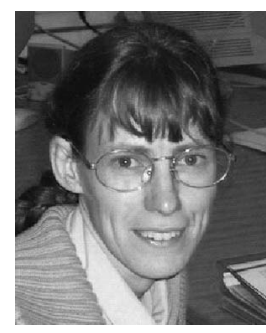

Judith Apsley (M'05) received the B.A. degree from Cambridge University, Cambridge, U.K., in 1986 , and the Ph.D. degree from the University of Surrey, Surrey, U.K., in 1996.

She was with Westland Helicopters (1982-1987), ERA Technology (1987-1995), and a small software company (1996-2001) before joining The University of Manchester (formerly University of Manchester Institute of Science and Technology), Manchester, U.K., as a Research Associate, where she has been a Lecturer since 2008. Her main research interests are modeling and control of electrical drives. 


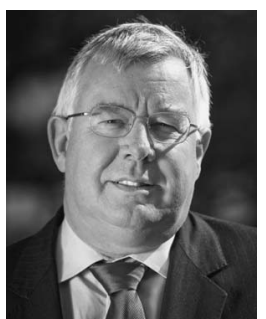

Steve Williamson (M'81-SM'88-F'95) received the Ph.D. degree from Imperial College, London, U.K.

He has spent a long career researching into induction motors. While most of that career has been spent at universities, he has always had strong links with the motor manufacturing industry and spent three years as the Technical Director of the last major U.K. manufacturer of die-cast cage machines. $\mathrm{He}$ is currently Deputy Vice-Chancellor for Research and Innovation at the University of Surrey, Guildford, U.K.

Dr. Williamson was the recipient of numerous prizes for his published work and was the recipient of the IEE Achievement Medal in 2000 and the IEEE Nikola Tesla Award in 2001.

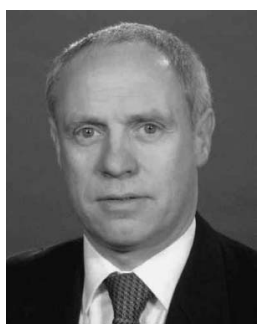

Alexander C. Smith (M'89-SM'02) received the B.Sc.Eng. and Ph.D. degrees from Aberdeen University, Aberdeen, U.K., in 1977 and 1980, respectively.

He has had academic appointments at Imperial College, London, U.K. (1983-1990), and at the University of Cambridge, Cambridge, U.K. (1990-1997). In 1997, he was with Invensys Brook Crompton as Head of Research responsible for motor technology. Since 2000, he has been with The University of Manchester (formerly University of Manchester Institute of Science and Technology), Manchester, U.K., where he has been a Professor of electrical machines in the School of Electrical and Electronic Engineering since 2007. He has been the Director of the Rolls-Royce University Technology Centre on Electrical Systems for Extreme Environments, The University of Manchester, since 2004. His research interests include design and modeling of motors, generators, and drives.

Dr. Smith is a Fellow of the Institute of Engineering and Technology (formerly Institution of Electrical Engineers (IEE), U.K.) and the past Chairman of the IEE Professional Network-Power Conversion and Applications.

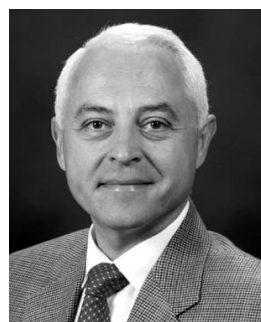

Dan M. Ionel (M'91-SM'01) received the M.Eng. and $\mathrm{Ph} . \mathrm{D}$. degrees in electrical engineering from the Polytechnic University of Bucharest, Bucharest, Romania.

His doctoral program included a Leverhulme Visiting Fellowship at the University of Bath, Bath, U.K. After completing postdoctoral work at the SPEED Laboratory, University of Glasgow, Glasgow, U.K., he was a Senior R\&D Engineer with the Invensys Brook Crompton Company, Huddersfield, U.K. $\mathrm{He}$ is currently the Electromagnetics Engineering Fellow at the A. O. Smith Corporate Technology Center, Milwaukee, WI.

Dr. Ionel has published more than 50 journal and conference papers, including a first prize winner of the IEEE Industry Application Society Electric Machine Committee. He is the holder of 20 U.S. patents and three European patents, including a medal winner at the Geneva Invention Fair. 